\section{AKADEMOS}

\section{ISSN: 1995-4743}

Año 13 Vol. $2, n^{\circ} 33$

AKADEMOS es una revista semestral. De amplio espacio editorial, para la publicación de trabajos inéditos de investigación, artículos de análisis, reseñas y opinión, en los distintos tópicos de las ciencias, la tecnología, las artes y la cultura.

\title{
Análisis de un poema de Manuel Gutiérrez Nájera: \\ La duquesa Job explicada
}

\section{Carmen González Huguet}

Poeta y escritora salvadoreña, Licenciada en Letras, Docente Investigadora, Escuela de Ciencias de la Comunicación, Universidad Dr. José Matías Delgado carmengonzalezh@yahoo.com

\section{Análisis extrínseco}

\subsection{Reseña biográfica del autor}

El futuro periodista, escritor, cirujano y poeta Manuel Gutiérrez Nájera nació en la ciudad de México, en la calle del Esclavo número 2, hoy calle República de Chile número 13 , el 22 de diciembre de 1859.

Perteneciente a una familia de clase media, fue el primogénito del matrimonio de Manuel Gutiérrez de Salceda Gómez (18181889), y María Dolores Nájera Huerta
(1831-1895). Lo bautizaron en la Iglesia del Sagrario Metropolitano con los nombres de Manuel Demetrio Francisco de Paula de la Santísima Trinidad Guadalupe Ignacio Antonio Miguel Joaquín, el día 4 de enero de 1860. Sus padrinos fueron el futuro funcionario José Yves Limantour Marquet (1854-1935), político y principal financiero del período conocido como porfiriato, y los tíos del futuro poeta: José Nájera Huerta y María Gertrudis Gutiérrez. Hay que hacer notar que el flamante padrino Limantour contaba escasos cinco años de edad cuando su ahijado fue bautizado. 
Debido al trabajo de Gutiérrez Nájera como médico, y para poder reciclar algunos trabajos periodísticos, el escritor solía usar numerosos pseudónimos. Por ejemplo: "El Cura de Jalatlaco", "El Duque Job", "Puck", "Junius", "Recamier", "Mr. Can-Can", "Nemo" y "Omega", entre otros, aunque el más conocido fue "Duque Job".

Algunas fuentes ${ }^{1}$ señalan que, más que pseudónimos, tales personajes fueron verdaderos heterónimos del escritor. Aunque muy pocas veces salió de la ciudad de México, salvo breves excursiones a Veracruz, Querétaro y otros lugares dentro de la república mexicana, gustó mucho de la cultura francesa, en especial de la poesía de autores como Alfred de Musset (1810-1857), Theophile Gautier (1811-1872) y Charles Baudelaire (1821-1867), entre otros. Pero también, a instancias de su madre, leyó a los grandes poetas del Siglo de Oro, especialmente a los místicos españoles como Santa Teresa de Jesús (1515-1582) y San Juan de la Cruz (1542-1591).

\subsection{Sus obras principales}

Gutiérrez Nájera se inició muy joven, prácticamente adolescente, como periodista, y siempre combinó su trabajo para los periódicos con su obra literaria. Fundó $\mathbf{L a} \mathbf{R e}$ vista Azul junto con el veracruzano Carlos Díaz Dufoo (1861-1941), publicación que lideró el modernismo en México durante dos años, del 6 de mayo de 1894 a octubre de 1896. El secretario de redacción era el poeta Luis Gonzaga Urbina. La revista era el suplemento dominical del periódico El Liberal, que funcionó en un edificio de la calle Independencia, número 19, en el centro histórico de la capital de México. A lo largo de su breve carrera literaria, Gutiérrez Nájera descolló con especial mérito como cuentista, habiendo publicado en vida Cuentos frágiles y Cuentos color de humo.

Una versión sobre su muerte apunta a que, al parecer, su condición de hemofílico era desconocida. Se sometió a una operación quirúrgica de rutina que se complicó y falleció el 3 de febrero de 1895, en su ciudad natal, cuando contaba apenas treinta y cinco años de edad. Sus restos reposan en el Panteón Francés de la ciudad de México.

\subsection{Movimiento literario al que perteneció}

Gutiérrez Nájera se inscribe dentro de las filas del modernismo. Para algunas fuentes es "un precursor". Para otros, es un escritor plenamente modernista. Excede los límites de este trabajo definir de modo extenso qué es el modernismo. Sin embargo, conviene esbozar, siquiera de modo somero, o intentar dar una idea de en qué consiste dicho movimiento en cuanto fenómeno literario.

1 Ver Pacheco, José Emilio (2000). Manuel Gutiérrez Nájera: el sueño de una noche porfiriana. En Letras Libres. Ciudad de México. Versión digital: https://www.letraslibres.com/mexico/manuel-gutierrez-najera-el-sueno-una-noche-porfiriana, consultada el 23 de octubre de 2019. 
Arqueles Vela, en su obra El modernismo: su filosofía, su estética, su técnica, nos dice: "El modernismo es la confluencia del espíritu moderno del mundo antiguo, y del espíritu antiguo del mundo moderno: síntesis de las inquietudes, ideales, sentimientos, ideas, de una clase que alcanza su plenitud cultural en los anales helénicos, y su universalismo económico-político, desde 1848". Y añade: "la energía citadina, propulsora del florecimiento de la polis, de la urbe, culmina en los tumultuosos centros industriales y comerciales del siglo XIX, y comienza a declinar en la cosmópolis maquinística del siglo XX. A la primera época - estadio de la burguesía revolucionaria- corresponden los románticos; a la segunda —estancia de la burguesía estabilizada en la plenitud de sus ideales - los parnasianos; a la tercera - Lapso de la disolución de los valores burgueses- los simbolistas, impresionistas, futuristas, etc."

Afirma José Emilio Pacheco: "Los modernistas parecen nuestros contemporáneos en muchos sentidos. Sus problemas tienen gran semejanza con los actuales. Sin embargo, nadie ha querido darnos la historia ni la antología del modernismo mexicano. Quizás ello se deba a dos dificultades. La primera es puramente literaria: la complicación de hacer un deslinde entre lo que es y no es modernismo. De acuerdo con la teoría "oficial", nuestro modernismo queda limitado a las obras de Efrén Rebolledo y Rafael López y a una parte de lo que escribieron Amado Nervo y José Juan Tablada. Gutiérrez Nájera y [Salvador] Díaz Mirón resultan "precursores", [Luis Gonzaga] Urbina "último romántico", [Manuel José] Othón "cima de la poesía neoclásica", que se opuso a los modernistas en cuanta oportunidad se le presentó; Ramón López Velarde y Francisco González León "poetas de la provincia"; Enrique González Martínez viene a ser finalmente el ángel exterminador... La segunda dificu1 tad es política: el porfiriato no produjo al modernismo, como podría sostener un determinista; pero, naturalmente, el modernismo estuvo condicionado por el porfiriato $^{3}$. Y lo que es peor: casi todos los modernistas fueron huertistas ${ }^{4}$. Para com-

2 Vela, Arqueles (2005). El modernismo: su filosofía, su estética, su técnica. Ciudad de México, Ed. Porrúa. ISBN 970-07-5740-4, pág. 9. Es importante señalar que este autor dedica la tercera parte de esta obra, de las páginas 57 a la 70, a la obra de Gutiérrez Nájera. Arqueles Vela (1899-1975) fue un escritor, académico y periodista que utilizó el pseudónimo literario Silvestre Paradox, aunque se sabe que también otros escritores publicaban bajo ese mismo pseudónimo. No se sabe con exactitud si nació en Tapachula, México, o en la república de Guatemala. Su hermano David Vela fue un destacado intelectual guatemalteco. El propio Arqueles Vela vivió durante un tiempo en Guatemala. De formación normalista, estudió en varias capitales europeas, como Roma, París, Madrid y Berlín antes de regresar a México, donde realizó una importante labor en la formación de maestros. Fue uno de los fundadores del Estridentismo, un movimiento literario que se originó en la ciudad de México. En la obra antes mencionada, Vela destaca el influjo de los poetas románticos, parnasianos, simbolistas y decadentistas, especialmente los franceses, en el nacimiento y la estética del Modernismo.

3 Porfiriato: época y régimen del presidente mexicano Porfirio Díaz (1830-1915), quien ocupó la presidencia de México durante treinta y cinco años, reeligiéndose siete veces y gobernando de facto desde 1876 hasta 1911. Esta etapa daría paso a la revolución mexicana.

4 Huertista: partidario de José Victoriano Huerta (1845-1916), ingeniero y presidente de México entre 1913 y 1914. Llegó al poder a través de un golpe de estado conocido como la Decena Trágica, en la que fueron asesinados el presidente Francisco I. Madero y el vicepresidente José María Pino Suárez. El efímero gobierno de Huerta terminaría con su derrota a manos del ejército constitucionalista al mando de Venustiano Carranza. 
prender el modernismo hay que estudiar el lenguaje de fin de siglo. Sin el dominio de esta lengua muerta no hay entendimiento posible. Los poemas deben verse bajo las categorías de la literatura europea de la época y situarse en las condiciones locales en que se produjeron, evitando $\cdot$ el peligro de que los contextos nos hagan perder de vista los textos". 5

Pero, a todo esto, ¿qué es el modernismo? En su libro Breve historia del modernismo, el escritor dominicano Max Henríquez Ureña $a^{6}$ sostiene: "Las dos últimas décadas del siglo XIX señalaron el advenimiento de una revolución literaria que abarcó en su órbita a todos los pueblos de habla española en el Nuevo Mundo y que, posteriormente, se extendió a España. El nombre que se aplicó a ese movimiento fue el de modernismo, que, a pesar de su muy discutible propiedad, ha subsistido en la historia literaria". El modernismo es, pues, un movimiento literario originado en Hispanoamérica. Por primera vez un movimiento no surgía en Europa y cruzaba el Atlántico para llegar al llamado Nuevo Mundo. Al revés: surgió en estas costas y de aquí irradió su influjo al resto del planeta. Y añade el mismo autor: "El movimiento modernista que en el orden literario se promovió en la América de habla española obedeció a diversas tendencias del periodo posromántico, similares a las que se habían manifestado en otras literaturas, especialmente de Francia, donde con el parnasianismo se entronizó el culto de la forma y con el simbolismo se renovaron, además del idearium poético, los modos de expresión y la técnica del verso... El modernismo fue, ante todo, un movimiento de reacción contra los excesos del romanticismo, que ya había cumplido su misión e iba de pasada, y contra las limitaciones y el criterio estrecho del retoricismo seudoclásico... El punto de partida del modernismo fue simplemente negativo: rechazar las normas y las formas que no se avinieran con sus tendencias renovadoras y representaran, en cambio, el viejo retoricismo que prevalecía en la literatura española de aquel momento. Hacer la guerra a la frase hecha, al clisé de forma y al clisé de idea. Modernista era todo el que volvía la espalda a los viejos cánones y a la vulgaridad de la expresión. En lo demás, cada cual podía actuar con plena independencia". ${ }^{7}$

En El Salvador, como tanto se ha dicho, la renovación modernista se inició con los intentos de Francisco Gavidia de adaptar al castellano el ritmo del verso alejandrino francés de Víctor Hugo. Es notable la traducción gavidiana del poema Stella, de Víc-

5 Pacheco, José Emilio (1999). Antología del modernismo (1884-1921). (Tomos I y II en un volumen). Ciudad de México, UNAM y Ediciones Era. ISBN 968-36-6156-4 (UNAM). ISBN 968-411-434:6 (Era)

Henríquez Ureña, Max (1962). Breve historia del modernismo. Ciudad de México, Fondo de Cultura Económica. Sin ISBN.

Henríquez Ureña, Max (1962). 0. c. págs. 11 y ss.

Jiménez Cervantes-Arnao, María del Mar (2008). Un análisis de la traducción de "Stella" de Víctor Hugo, por Francisco Gavidia. Artículo publicado en Cartaphilus. Revista de investigación y crítica estética. Hay versión digital en: https://revistas.um.es/cartaphilus/article/ view/23561, consultado el 28 de octubre de 2019. 
tor Hugo ${ }^{8}$. Gavidia mostró sus hallazgos a Rubén Darío, durante una inicial estadía del poeta nicaragüense en suelo salvadoreño, del 7 de agosto de 1882 al 18 de octubre de 1883. En esa época ambos poetas eran adolescentes: a su llegada a El Salvador Darío contaba quince años, y Gavidia aproximadamente diecinueve.

En el ámbito hispanoamericano las principales figuras del modernismo han sido el poeta nicaragüense Rubén Darío, los colombianos José Asunción Silva y Guillermo Valencia; los peruanos José Santos Chocano, Aurora Cáceres, Clemente Palma Román, Manuel González Prada y Ventura García Calderón; los uruguayos Julio Herrera y Reissig y Delmira Agustini; los venezolanos Rufino Blanco Fombona, Manuel Díaz Rodríguez y Rómulo Gallegos; los argentinos Leopoldo Lugones y Enrique Larreta; el escritor boliviano Ricardo Jaimes Freyre; el chileno Carlos Pezoa Veliz; los costarricenses Lisímaco Chavarría y Rafael Ángel Troyo; los cubanos José Martí y Julián del Casal; el dominicano Manuel de Jesús Galván; los ecuatorianos
Ernesto Noboa y Caamaño, Arturo Borja, Humberto Fierro y Medardo Ángel Silva; y los españoles Antonio y Manuel Machado, Francisco Villaespesa, Juan Ramón Jiménez, Salvador Rueda y Eduardo Marquina, entre otros. En Guatemala destacó el cronista Enrique Gómez Carrillo. En México son dignos de mención Amado Nervo, Salvador Díaz Mirón, Luis Gonzaga Urbina, Enrique González Martínez y José Juan Tablada. En El Salvador se destacaron el ya citado Francisco Gavidia, así como los poetas Vicente Acosta y Vicente Rosales y Rosales. En la prosa modernista salvadoreña el más importante autor es Arturo Ambrogi.

\subsection{Ambientación social, política, económica y/o religiosa del autor y su época}

Rodrigo Figueroa Obregón menciona: “José Emilio Pacheco... apunta la importancia de que La duquesa Job, publicado en 1884", sea "el primer poema que se escribe para una clase media urbana" (XL). Pacheco apunta dos hechos de capital importancia: este poema es

9 En 1884 Manuel Gutiérrez Nájera contaba aproximadamente veinticinco años de edad.

10 Figueroa Obregón, Rodrigo (2019). Espacio político en “La duquesa Job” de Manuel Gutiérrez Nájera. En Decimonónica. Journal of Nineteenth Century Hispanic Cultural Production. Revista de Producción Cultural Hispánica Decimonónica. Vol. 16, No. 1. Párrafo completo: “La crítica especializada ha revalorado el legado de Manuel Gutiérrez Nájera (México, D.F., 1859-1895), sobre todo a la luz de sus crónicas y sus escritos políticos, cuya recuperación se debe en gran medida a Erwin K. Mapes y Boyd G. Carter. Si bien se solía considerar a Gutiérrez Nájera como el escritor por antonomasia que habitaba y escribía desde su torre de marfil, los trabajos de los académicos antes mencionados trajeron a la luz un corpus de textos que lidian directamente con la política y el mundo de su tiempo. Por ende, la lectura de la crónica de Gutiérrez Nájera se ha hecho en los últimos años desde la perspectiva política, desde la visión de un autor que efectivamente interactúa con su mundo y desea transformarlo (Hernández Ramírez 25; Pascual Gay 15; Martínez et al. 167). Desafortunadamente, tanto la prosa como la poesía de nuestro autor tiende a leerse como se solía hacer: como textos preciosistas que no se enfrentan a la realidad social y política de su tiempo. José Emilio Pacheco, sin embargo, apunta la importancia de que La duquesa Job, publicado en 1884, sea "el primer poema que se escribe para una clase media urbana" (XL). Pacheco apunta dos hechos de capital importancia: este poema es sobre y para una clase social, y esta tiene un espacio que, como veremos, está cargado de un imaginario político". Fin de la cita. 
sobre y para una clase social, y esta tiene un espacio que, como veremos, está cargado de un imaginario político..."10. Ya apuntaba al carácter marcadamente urbano del Modernismo el citado autor Arqueles Vela.

José Emilio Pacheco señala, además: "El espacio urbano de la Ciudad de México estaba profundamente dividido durante el porfiriato en función de clase socioeconómica: al este del Zócalo, los trabajadores, y al oeste, la burguesía. Esta división se reproduce implícitamente también en el poema de Gutiérrez Nájera, y el punto en el que las dos clases se encuentran es la calle de Plateros", 11 una vía que precisamente se menciona en el poema que vamos a analizar.

\section{Análisis intrínseco}

\subsection{Tema o asunto: ¿¿De qué habla el poema?}

Al parecer, Gutiérrez Nájera no solo era un francófilo de pura cepa en sus gustos literarios. Algunas fuentes ${ }^{12}$ señalan que tuvo una relación sentimental con una señorita francesa: Marie Rose Alphonsine Remy, mencionada por José Emilio Pacheco (2000) en el artículo antes citado. Dice la fuente: "Hasta hoy uno creía que el poema era la encarnación real de un prototipo leído en las novelas ajenas y dibujado en las narraciones y los versos propios. Marie, la griseta francomexicana, nos parecía la versión local de la muchacha proletaria que en su variante vienesa surge en las obras de Arthur Schnitzler y oscila entre la obrera y la cortesana. (Según Émile Zola, la escala en París era grisette, lorette, cocotte). La niña pobre divierte al joven rico que está casado o se casará con otra chica nada pobre. Cuando Gutiérrez Nájera se une a Cecilia Maillefert... fue como casarse con la literatura francesa ya que su padre vendía los libros en este idioma. Marie intenta el suicidio con fósforos disueltos en té (versión de Manuel Puga y Acal, a quien está dedicado el poema y que decía haber sido amigo en París de Rimbaud y Verlaine en un momento en que el primero se encontraba ya muy lejos y el segundo se hallaba preso en Bélgica). Otra eminente najeróloga, Irma Contreras García, publica en San Cristóbal de las Casas La verdadera Duquesa Job. Marie Rose Alphonsine Remy diseñaba sombreros en el almacén de Madame Anciaux... El periodista pobretón no era un buen partido: Marie se casó con Guillermo Morales, alto empleado de otro almacén francés. Quizá hubiera sido mejor quedarse con la velada sexualidad del texto ("Después, ligera, del lecho brinca. / Oh quién la viera cuando se hinca/ blanca y esbelta sobre el colchón!'), no encontrarnos con la foto, se-

11 Figueroa Obregón (2019). 0. c. La antigua calle de Plateros es hoy la Avenida Francisco I. Madero. En ella se levantan la famosa Torre Latinoamericana, la Casa de los Azulejos, el Palacio de Iturbide y la Iglesia de San Francisco, entre otros edificios importantes de la ciudad de México.

12 Importante información sobre este autor y este poema se encuentra en el artículo de José Emilio Pacheco (2000) publicado en Letras Libres y citado arriba. Ver: https://www.letraslibres.com/mexico/manuel-gutierrez-najera-el-sueno-una-noche-porfiriana, consultado el 28 de octubre de 2019. 
guirle poniendo sucesivos rostros y cuerpos, ayer de Brigitte Bardot, hoy de Laetitia Casta. Tal vez nunca hubo nada entre ellos y a esa ausencia debemos el poema, escrito como defensa, diría Pavese ${ }^{13}$, contra las ofensas de la vida....". ${ }^{14}$ Fin de la cita.

En el poema aparece una serie de personas y de palabras desconocidas para los lectores del siglo XIX. En primer lugar: ¿quién es Manuel Puga y Acal (1860-1930), el personaje al que Gutiérrez Nájera dedicó el poema? Se trata de un escritor mexicano nacido en Guadalajara y muerto en la ciudad de México. Fue poeta, periodista, catedrático, político, traductor, historiador y académico. Escribió con el pseudónimo de Brummel. Estudió en su ciudad natal y en Francia y Bélgica. De regreso a México, impartió clases en la Escuela Nacional Preparatoria y en la de Altos Estudios. Como periodista mantuvo polémicas con Salvador Díaz Mirón (1853-1928), Juan de Dios Peza (1852-1910) y el propio Manuel Gutiérrez Nájera.

Griseta es la traducción española a la palabra francesa grisette, que aludía inicialmente a una tela gris ordinaria, de la que se confeccionaban los uniformes de las trabajadoras de la industria de la confección de ropa en el siglo XIX y principios del XX. Las grisetas Museta y Mimí, así como el poeta Rodolfo y el filósofo Schaunard aparecen en la novela Escenas de la vida bohemia, del escritor francés Henri Murger (1822-1861), la cual fue adaptada, tomándose muchas libertades, eso sí, para el libreto de la famosa ópera La Bohème, de Ruggero Leoncavallo (1857-1919), estrenada en el teatro La Fenice, en Venecia, el 6 de mayo de 1897. Esta ópera, sin embargo, cayó en la oscuridad, no pudiendo superar la popularidad de la que escribió Giacomo Puccini (1858-1924), con el mismo título y asunto, estrenada un año antes que la de Leoncavallo.

La duquesa Job, así como la persona real en que se inspira: Marie Rose Alphonsine Remy, trabajaron en la industria de la confección de su época. Marie confeccionaba sombreros para madame Ancieux, modista de la ciudad de México cuyo establecimiento se localizaba en la ya mencionada calle de Plateros. Aunque de clase trabajadora, las grisetas eran mujeres independientes desde el punto de vista económico, lo cual era, con seguridad, algo nuevo en el siglo XIX. En Argentina, donde también se asentaron estas inmigrantes francesas, en 1924 se estrenó un tango titulado precisamente Griseta, con letra escrita por José González Castillo y música de Enrique Pedro Delfino.

Por otra parte, en la estrofa número dos, el poeta menciona a José María Villasana (1845-1904), célebre caricaturista mexicano, precursor de los cómics o historietas, quien

13 Cesare Pavese (1908-1950): escritor italiano y traductor. Se licenció en filología inglesa por la Universidad de Turín, en 1932, con una tesis sobre el poeta estadounidense Walt Whitman (1819-1892). Pavese fue uno de los fundadores de la editorial Einaudi. Fue aprisionado a partir de 1935 por sus ideas antifascistas. Después de la Segunda Guerra Mundial se afilió al Partido Comunista Italiano.

14 Pacheco, José Emilio (2000). 0. c. 
publicó la primera historia de este tipo en $\mathbf{L a}$ ilustración potosina, periódico en el que publicó la novela gráfica Rosa y Federico, que tal vez. fuera la primera historieta publicada en el país azteca. Villasana también participó en las publicaciones México y sus costumbres (1872), La historia danzante (1874), y El Ahuizote (1874-76), entre otras.

En cuanto a "la poblana de enagua roja que Prieto amó", alude al político, poeta y escritor Guillermo Prieto Pradillo (1818-1897), partidario de Benito Juárez, al que salvó la vida en Guadalajara gritando su famosa frase: "Los valientes no asesinan" cuando el conservador Filomeno Bravo había dado la orden a soldados del Quinto regimiento de fusilar al presidente. Algunas fuentes señalan: "En 1890 [Prieto] resultó ganador del concurso convocado por el periódico La República para determinar quién era el poeta más popular del momento, superando a los también poetas mexicanos Juan de Dios Peza y Salvador Díaz Mirón. Fue declarado por Ignacio Manuel Altamirano (1834-1893) como "El poeta mexicano por excelencia, el poeta de la patria" desde su Observatorio de Costumbres. En su obra, Prieto vio desfilar paisajes urbanos y tipos populares y los describió con una novedad plástica asombrosa, al tiempo que sostuvo siempre su pasión política. bajo su tono festivo e irónico. Autor fecundo, su obra com- pleta aún está dispersa en periódicos. De su poesía sobresalen La musa callejera y Romance Nacional, en tanto que de su prosa destacan Memorias de mis tiempos, Viajes de orden supremo y Viajes a los Estados Unidos". ${ }^{15}$

El bloguero don Susanito, pseudónimo de Francisco Báez Rodríguez, periodista mexicano y columnista del periódico La Crónica de Hoy, afirma: "Gutiérrez Nájera inicia el retrato describiendo lo que no era Marie. No era una falsa condesa presumida, como las que dibujaba el gran caricaturista José María Villasana. Tampoco una vulgar china poblana. Tampoco una sirvienta de pies descalzos o una arribista a la caza de juniors de pelo engominado ("los gomosos")", personajes que también, probablemente, cultivaban la costumbre de engominarse los bigotes. La misma fuente afirma la existencia de un diputado de apellido Micoló, aficionado a organizar peleas de gallos ${ }^{16}$, eventos a los que asistían los "los nuevos ricos". El bloguero concluye: "En otras palabras, la duquesa no era poser, ni naca, ni gata, ni fresa, ni chaka, como se diría hoy".

La misma fuente abunda sobre el término griseta explicado arriba: "Las grisettes originales eran costureras y obreras que vestían de gris. Estas mujeres, por tener ingresos propios, podían darse libertades que otras no

15 Fuente: https://vanguardia.com.mx/esconocidoguillermoprietocomoelpoetamexicanoporexcelencia-117863.html\#: :targetText=M\%C3\%A 9xico.\%2D\%20El\%20escritor\%2C\%20poeta, 10\%20de\%20febrero\%20de\%201818., consultado el 13 de noviembre de 2019.

16 Según otras fuentes, Pedro Micoló fue un peluquero de origen francés que se estableció en la ciudad de México. A su establecimiento acudían los petimetres y señoritos de la aristocracia de la época. al parecer, el señor Micoló acostumbraba adornar su local con figuras de gallos. Fuente: Panorama mexicano: 1890-1910, de Ciro B. Ceballos. 
podían, como escoger abiertamente su pareja. Una griseta es, por definición, coqueta y ligadora, pero no es una prostituta, sino una mujer independiente, que frecuenta los ambientes bohemios. Marie no era costurera u obrera, sino empleada en una gran tienda de lujo". ${ }^{17}$

En cuanto a Paul de Kock, se trata del novelista y dramaturgo francés Charles-Paul de Kock, nacido en Passy el 21 de mayo de 1793, y fallecido el 29 de agosto de 1871, en Romainville. Fue hijo del banquero holandés Jean Conrad Kock (1755-1794), quien murió guillotinado durante el período denominado "El Terror". Paul de Kock vivió gran parte de su vida en el parisino Bulevar Saint-Martin, en la zona de los grandes bulevares de la capital francesa. Tuvo una vida acomodada gracias a sus rentas, lo que le permitió dedicarse a la literatura. Escribió una serie de exitosas novelas en las que describió la vida cotidiana de la clase media del París de su época, serie inaugurada con su novela Georgette, publicada en 1820. Su producción se decantó por la novela por entregas, que tan popular fue durante el siglo XIX, vistos los ejemplos de Alejandro Dumas padre (18021870), Eugène Sue (1804-1857) y Paul Féval (1816-1887), y, en España, del padre Luis Coloma (1851-1915) y de Benito Pérez Galdós (1843-1920), entre muchos otros.

Paul de Kock fue un autor sumamente prolífico, habiendo publicado, según ciertas fuentes, cien novelas, y según otras cerca de cuatrocientas obras de narrativa y unas doscientas destinadas a la escena teatral, entre dramas y libretos para ópera y vodevil, no desprovistas, según algunos autores, como Chateaubriand, de genio ni de sentido del humor. Fue padre del también escritor Henri de Kock (1819-1892).

En cuanto a bailar el "boston" y a otros términos que aparecen en la tercera estrofa, Francisco Báez Rodríguez, en su ya citado blog, afirma: "Boston Waltr es el nombre que se le daba al vals americano, mucho más lento que el aceleradísimo vals vienés. Las carreras que se refiere son a las de caballos, en los hipódromos de Peralvillo y de la Condesa. El five O'clock es, por supuesto, la hora del té".

En la estrofa número cuatro, los querubes que vio Jacob se refieren a un pasaje del libro del Génesis, en la Biblia: Gen. 28, 11 19. Se describe ahí el sueño que tuvo el patriarca Jacob durante su huida de la casa de su padre Isaac, luego de haber suplantado a su hermano Esaú con el fin de obtener la primogenitura. En aquella época el patriarca Isaac era muy anciano y estaba casi ciego. Jacob se durmió en un descanso en el camino y soñó con una larga escalera que subía de la Tierra al cielo, por la que ascendían y luego descendían varios ángeles.

La calle Plateros que se menciona en la estrofa número cinco ya vimos que es la ac-

17 Fuente: https://vanguardia.com.mx/esconocidoguillermoprietocomoelpoetamexicanoporexcelencia-117863.html\#: :targetText=M\%C3\%A 9xico.\%2D\%20El\%20escritor\%2C\%20poeta,10\%20de\%20febrero\%20de\%201818., consultado el 13 de noviembre de 2019. 
tual Avenida Francisco I. Madero. La madame Marnat ahí mencionada es una modista francesa muy reputada en su época. Francisco Báez Rodríguez afirma que madame Marnat era: “...dueña de la casa de vestidos más famosa de la época (recordemos que la mayor parte de los ajuares eran hechos a mano y a la medida). Aquí el uso del "sin disputa" es para jugar con las confusiones. Don Manuel juega a que Mme. Marnat quisiera vestir a Marie, pero en realidad "sin disputa" quiere decir "sin duda". En realidad, la duquesa Job va a casa de otra modista más modesta...".

En la estrofa número seis aparecen dos galicismos. La misma fuente sostiene: "V'lan y pschutt son dos palabras que eran usadísimas en Francia a principios de los años ochenta del siglo XIX. Guy de Maupassant en algún texto se queja de que estos dos vocablos estaban asesinando la lengua francesa, porque se usaban para todo. Serían hoy el equivalente de "chido", aunque un Gutiérrez Nájera contemporáneo sería agringado y utilizaría el vocablo “cool”. Hèlene Kossut era la modista más renombrada en el México de entonces, es decir, de la década de 1884: ni en sueños una griseta hubiera podido comprar alguna de sus prendas. Esta es la frase clave del poema, porque se trata de un paseo por Plateros, de la recuperación del espacio urbano, antes hosco y hostil, por una mujer normal y por un hombre que espera su salida del trabajo...".

En la estrofa número siete nos encontramos con las puertas de "La Sorpresa" y con "la esquina del Jockey Club". Al respecto, el mismo autor nos explica: "La Sorpresa era un almacén casi esquina con el Zócalo, espacio femenino, y el Jockey Club, un masculino restaurante de postín en la [actual] Casa de los Azulejos. Es como si dijéramos "de Perisur a Mazaryk".

En la siguiente estrofa, la ocho, nos encontramos con: "Las baldosas, el meneo, el coqueteo, todos símbolos de modernidad mundana en una ciudad que va dejando el luto. El paso del botín de Marie guía el ritmo del poema. Y Mimí Pinsón, como definición final: la quintaesencia de la griseta de la belle époque". Mimí Pinsón es un personaje de un relato corto del poeta francés Alfred de Musset. (1810-1857) publicado en 1845. La narración lleva como subtítulo la frase: "Profil de Grisette". Es decir: perfil de una griseta. Ya explicamos el término anterior. Sobre este personaje el director Theo Bergerat filmó y estrenó una película muda en Francia, en 1924. Anteriormente, en 1915, Mimí Pinsón fue tema de una opereta compuesta por Henri Goublier, con libreto de Maurice Ordoneau.

En la estrofa nueve aparece el término "tuno". El Diccionario de la Lengua Española lo define, en su acepción primera, como "pícaro, tunante", y, en su cuarta acepción: vida libre y vagabunda.

Por otra parte, en la estrofa diez, el poeta dice. "sprint rociado de Veuve Clocquot". Hoy sprint es una compañía telefónica. La palabra, nos dice el citado Diccionario, es un anglicismo, y nos ofrece estas dos acepcio- 
nes: 1. m. Dep. Aceleración que realiza un corredor en un tramo determinado de la carrera, especialmente en la llegada a meta para disputar la victoria a otros corredores. Y 2. m. Esfuerzo final que se realiza en cualquier actividad". En cuanto a la Veuve Clicquot Ponsardin, se trata, hoy en día, de una casa francesa, con sede en la ciudad de Reims, especializada en la fabricación de una de las marcas más finas de champán. Fue fundada en 1772 by Philippe Clicquot, banquero, industrial textil y propietario de viñedos en la región francesa de Champagne. Francois, el hijo de Philippe, se casó el 10 de junio de 1798 con Barbe-Nicole Ponsardin, hija de Nicolás Ponsardin, un rico empresario francés. En 1805 Francois murió repentinamente y su padre, que lo había hecho socio de la firma, pensó en cerrar, pero Barbe-Nicole, la viuda de Francois y nuera de Philippe, decidió hacerse cargo de la empresa, aunque solo contaba veintisiete años de edad. Nació así la marca "Veuve Clicquot": “", en francés, es "viuda".

Louise Theo, en cambio, fue una cantante de opereta nacida y muerta en París, y bautizada originalmente con el nombre de Cécile Piccolo (1854-1922). Fue muy famosa en los años entre 1870 y 1900, habiendo realizado giras por los Estados Unidos y aparecido en operetas compuestas por el músico germano-francés Jacques Offenbach (1819-1880). Louise Theo se casó con un rico marchante de arte neoyorkino, lo cual puso fin a su carrera artística.

En la estrofa 11 nos topamos con varios términos que tal vez hoy nos suenen extraños: gola es un adorno que llevaban antiguamente los vestidos a la altura del cuello. Corsé, por otra parte, era una prenda de lencería cuya finalidad era afinar la cintura de las damas que lo usaban. Hay una escena que muestra la operación de apretarse el corsé llevada a cabo por la mucama Mamie, quien aprieta las cuerdas que el corsé llevaba a la espalda para que Scarlett O'Hara pudiera lucir su breve cintura en la película de 1939 Lo que el viento se llevó, basada en la novela de la escritora estadounidense Margaret Mitchell. Precisamente el Diccionario de la Lengua Española define la palabra "corsé" como: "Prenda femenina armada con ballenas, usada para ceñirse el cuerpo desde el pecho hasta las caderas". Las "ballenas" a que alude el diccionario se extraían de las barbas de las ballenas. Estos fragmentos óseos no se deformaban y permitían que la prenda se mantuviera en su lugar.

En cuanto a "crac", que no tiene nada qué ver con el estupefaciente derivado de la cocaína, la misma fuente lo define como: "onomatopeya usada para imitar el sonido de algo que se quiebra". Podría aludir a los fragmentos óseos de ballena utilizados en el diseño del corsé. Por otra parte, el adjetivo "cuca", dice el mismo diccionario, significa de modo coloquial: "pulido, mono". Esto es: bonita, agradable, simpática.

En la estrofa número 12 nos topamos con la palabra "arremango". El Diccionario de la Lengua Española define "remangarse" como: "Levantar, recoger hacia arriba las mangas o la ropa", y coloquialmente. "tomar enérgicamente una resolución". De modo 
que la expresión: "nada hay más bello que el arremango/ provocativo de su nariz", nos habla de una nariz respingona y resuelta.

En la misma estrofa, el poeta afirma: "Por ser tan joven y tan bonita/ cual mi sedosa, blanca gatita,/ diera sus pajes la emperatriz". ¿A qué emperatriz se refiere? Probablemente a la desdichada emperatriz Carlota (1840-1927), esposa del emperador Maximiliano I de México (1832-1867). A principios de la década de 1860, el emperador Napoleón III de Francia inició una intervención militar en el país azteca con el fin de convertirlo en un satélite de la nación gala. A ese fin, el matrimonio desembarcó en 1864 en el puerto de Veracruz. La pareja fue coronada en la Catedral de la ciudad de México el 10 de abril de 1864 y residió en el Castillo de Chapultepec. Sin embargo, aquella aventura neocolonialista salió mal. En 1866, el gobierno francés retiró sus tropas. Aunque la emperatriz viajó a Europa a fin de lograr el apoyo de las potencias para brindar ayuda a su esposo, este fue fusilado en Querétaro el 19 de junio de 1867. Carlota solo contaba veintisiete años al quedar viuda. Por ciertos rasgos de conducta que mostró durante las gestiones que realizara para que las cortes europeas o el papa ayudaran a su marido, se generalizó la opinión de que la emperatriz estaba loca.

En la estrofa número 13 no hallamos palabras difíciles. En cambio, el poeta nos ofrece dos indiscretas imágenes de su amada: la sorprende, primero, en el momento de pei- narse. Y luego en el proceso de bañarse, con brazos y garganta cubiertos de jabón.

En la estrofa número 14 asistimos al despertar de la bella francesa, que los domingos permanece en la cama hasta las nueve, mientras la criada madruga apara asistir a misa. En la estrofa siguiente, la 15, nos describe el ajuar de la joven que la aguarda para vestirse.

En la estrofa número 16 nos espera la palabra "cotillón". El Diccionario de la Lengua Española define esta palabra de la siguiente manera: "1. m. Fiesta y baile que se celebra en un día señalado como el de fin de año o Reyes. 2. m. Danza con figuras, y generalmente en compás de vals, que solía ejecutarse al fin de los bailes de sociedad. 3. m. Baile de sociedad en que al final se ejecutaba el cotillón". Se trata, pues, de un baile de la alta sociedad al que sin duda acudían las jóvenes de ricas familias y donde una "griseta" como Marie no tenía, presumiblemente, cabida alguna.

A pesar del alto nivel de confianza que denota el poema, para que no nos quepan dudas de que la joven pareja duerme en cuartos separados, el poeta afirma: "Toco, se viste, me abre; almorzamos...". Y a continuación nos comparte el menú del desayuno. Un menú ciertamente muy contundente: "un par de huevos y un buen beefsteak", acompañado de "media botella de rico vino". Y este es el preludio del paseo dominical por el "pintoresco" bosque de Chapultepec. Hoy ese anglicismo se ha convertido, y la RAE lo ha admitido con la grafía moderna, en nuestro cotidiano bistec. 


\section{2 ¿Cómo lo dice? Primera parte: Análisis métrico del poema:}

Se trata de un poema escrito en versos decasílabos. Este metro es poco habitual en la poesía en lengua española. José Domínguez Caparrós ${ }^{18}$ señala que el decasílabo se puede presentar como verso "simple" y como verso "compuesto", esto es, formado por dos hemistiquios de cinco sílabas cada uno: "En la primera forma su acentuación característica es en las sílabas tercera, sexta y novena, en el conocido como "decasílabo anapéstico" o "de himno". Este verso fue usado en los himnos patrióticos del siglo XIX, en poesía destinada al canto, y es prácticamente la única modalidad rítmica que se registra como forma del decasílabo uniforme en una composición entera". Como ejemplo, veamos un fragmento de nuestro himno nacional, cuya letra fue escrita, como bien sabemos, por el general y poeta Juan José Cañas (1826-1918):

\section{Tabla 1}

\begin{tabular}{l|l}
\multicolumn{1}{c|}{ Verso } & \multicolumn{1}{c}{ Acentos } \\
\hline Saludemos la Patria orgullosos & $3^{\mathrm{a}-6^{\mathrm{a}}-9^{\mathrm{a}}}$ \\
\hline De hijos suyos podernos llamar & $3^{\mathrm{a}-6^{\mathrm{a}}-9^{\mathrm{a}}}$ \\
\hline Y juremos la vida animosos & $3^{\mathrm{a}-6^{\mathrm{a}}-9^{\mathrm{a}}}$ \\
\hline Sin descanso a su bien consagrar & $3^{\mathrm{a}}-6^{\mathrm{a}-9^{a}}$ \\
\hline
\end{tabular}

En este ejemplo es evidente que cada verso presenta el siguiente esquema de ritmo: anacrusis bisílaba + dactílico + dactílico + trocaico:

(O-O) (Ó-O-O) (Ó-O-O) (Ó-O).

El decasílabo fue utilizado en la poesía romántica. El ejemplo más señalado quizás sea la Rima VII de Gustavo Adolfo Bécquer, cuyo primer verso dice: "Del salón en el ángulo oscuro...". También fue utilizado por José de Espronceda en su célebre poema El estudiante de Salamanca. Rubén Darío lo usó en su Rima IV, cuya primera estrofa dice:
Allá en la playa quedó la niña.

¡Arriba el ancla! ¡Se va el vapor!

El marinero canta entre dientes.

Se bunde en el agua trémula el sol...

La variante de este ejemplo es el que Tomás Navarro Tomás" ${ }^{19}$ llama: “decasílabo trocaico compuesto, y también es el que 
aparece con muchísima frecuencia en $\mathbf{L a}$ duquesa Job. Consta de dos pentasílabos trocaicos. Acentos en segunda y cuarta de cada hemistiquio. Variedad del polirrítmico correspondiente". Este es el ejemplo:

\section{Tabla 2}

\begin{tabular}{|c|c|}
\hline Verso & Acentos \\
\hline Allá en la playa// quedó la niña & $2^{a}-4^{a} / / 2^{a}-4^{a}$ \\
\hline
\end{tabular}

En cuanto a La duquesa Job, veamos el esquema de acentos:

\begin{tabular}{|c|c|c|c|}
\hline No. & Verso & Acentos en sílabas: & Observaciones \\
\hline & Estrofa 1: & & \\
\hline 1 & En dulce charla de sobremesa, & $2-4 / / 2-4$ & \\
\hline 2 & mientras devoro fresa tras fresa, & $1-4 / / 1-4$ & \\
\hline 3 & y abajo ronca tu perro Bob & $2-4 / / 2-4$ & \\
\hline 4 & te haré el retrato de la duquesa & $2-4 / / 2-4$ & \\
\hline \multirow[t]{2}{*}{5} & que adora a veces el duque Job. & $2-4 / / 2-4$ & \\
\hline & Estrofa 2: & & \\
\hline 6 & No es la condesa que Villasana & $2-4 / / 2-4$ & \\
\hline 7 & caricatura, ni la poblana & $2-4 / / 2-4$ & \\
\hline 8 & de enagua roja, que Prieto amó, & $2-4 / / 2-4$ & \\
\hline 9 & no es la criadita de pies nudosos, & $2-4 / / 2-4$ & \\
\hline 10 & ni la que sueña con los gomosos & $2-4 / / 2-4$ & \\
\hline \multirow[t]{2}{*}{11} & y con los gallos de Micoló. & $2-4 / / 2-4$ & \\
\hline & Estrofa 3: & & \\
\hline 12 & Mi duquesita, la que me adora, & $2-4 / / 2-4$ & \\
\hline 13 & no tiene humos de gran señora: & $2-4 / / 2-4$ & \\
\hline 14 & Es la griseta de Paul de Kock. & $2-4 / / 2-4$ & \\
\hline 15 & No baila "boston", y desconoce & $2-4 / / 2-4$ & \\
\hline 16 & de las carreras el alto goce & $2-4 / / 2-4$ & \\
\hline 17 & y los placeres del "five o'clock". & $2-4 / / 2-4$ & \\
\hline
\end{tabular}




\begin{tabular}{|c|c|c|c|}
\hline No. & Verso & Acentos en sílabas: & Observaciones \\
\hline & Estrofa 4: & & \\
\hline 18 & Pero ni el sueño de algún poeta, & $1-4 / / 2-4$ & \\
\hline 19 & ni los querubes que vio Jacob, & $2-4 / / 2-4$ & \\
\hline 20 & fueron tan bellos cual la coqueta & $1-4 / / 1-4$ & \\
\hline 21 & de ojitos verdes, rubia griseta, & $2-4 / / 1-4$ & \\
\hline \multirow[t]{2}{*}{22} & que adora a veces el duque Job. & $2-4 / / 2-4$ & \\
\hline & Estrofa 5: & & \\
\hline 23 & Si pisa alfombras, no es en su casa, & $2-4 / / 2-4$ & \\
\hline 24 & si por Plateros alegre pasa & $2-4 / / 2-4$ & \\
\hline 25 & y la saluda madame Marnat, & $2-4 / / 2-4$ & \\
\hline 26 & no es, sin disputa, porque la vista, & $2-4 / / 1-4$ & \\
\hline 27 & sí porque a casa de otra modista & $1-2-4 / / 1-4$ & Acento antirrítmico \\
\hline \multirow[t]{2}{*}{28} & desde temprano rápida va. & $1-4 / / 1-4$ & \\
\hline & Estrofa 6: & & \\
\hline 29 & No tiene alhajas mi duquesita, & $2-4 / / 1-4$ & \\
\hline 30 & pero es tan guapa, y es tan bonita, & $1-4 / / 2-4$ & \\
\hline 31 & y tiene un cuerpo tan v'lan, $\tan$ pschutt, & $2-4 / / 2-4$ & \\
\hline 32 & de tal manera trasciende a Francia, & $2-4 / / 2-4$ & \\
\hline 33 & que no la igualan en elegancia & $2-4 / / 1-4$ & \\
\hline \multirow[t]{2}{*}{34} & ni las clientas de Hélene Kossut. & $2-4 / / 2-4$ & Diástole en la palabra "clientas" \\
\hline & Estrofa 7: & & \\
\hline 35 & Desde las puertas de "La Sorpresa" & $1-4 / / 2-4$ & \\
\hline 36 & hasta la esquina del Jockey Club, & $1-4 / / 2-4$ & \\
\hline 37 & no hay española, yanqui o francesa, & $1-4 / / 1-4$ & \\
\hline 38 & ni más bonita ni más traviesa & $2-4 / / 2-4$ & \\
\hline \multirow[t]{2}{*}{39} & que la duquesa del duque Job. & $2-4 / / 2-4$ & \\
\hline & Estrofa 8: & & \\
\hline 40 & ¡Cómo resuena su taconeo & $1-4 / / 1-4$ & \\
\hline 41 & en las baldosas! ¡Con qué meneo & $2-4 / / 2-4$ & \\
\hline 42 & luce su talle de tentación! & $1-4 / / 1-4$ & \\
\hline 43 & ¡Con qué airecito de aristocracia & $2-4 / / 1-4$ & \\
\hline 44 & mira a los hombres, y con qué gracia & $1-4 / / 1-3-4$ & En amarillo acento antirrítmico \\
\hline 45 & frunce los labios! ¡Mimí Pinsón! & $1-4 / / 2-4$ & \\
\hline
\end{tabular}




\begin{tabular}{|c|c|c|c|}
\hline No. & Verso & Acentos en sílabas: & Observaciones \\
\hline & Estrofa 9: & & \\
\hline 46 & Si alguien la alcanza, si la requiebra & $2-4 / / 2-4$ & \\
\hline 47 & ella, ligera como una cebra, & $1-4 / / 1-4$ & \\
\hline 48 & sigue camino del almacén; & $1-4 / / 1-4$ & \\
\hline 49 & pero, jay del tuno si alarga el brazo! & $2-4 / / 2-4$ & \\
\hline 50 & ¡Nadie se salva del sombrillazo & $1-4 / / 1-4$ & \\
\hline \multirow[t]{2}{*}{51} & que le descarga sobre la sien! & $1-4 / / 1-4$ & \\
\hline & Estrofa 10: & & \\
\hline 52 & ¡No hay en el mundo mujer más linda! & $1-4 / / 2-4$ & \\
\hline 53 & pie de andaluza, boca de guinda, & $1-4 / / 1-4$ & \\
\hline 54 & sprint rociado de Veuve Clicquot, & $1-4 / / 2-4$ & \\
\hline 55 & talle de avispa, cutis de ala, & $1-4 / / 1-4$ & \\
\hline 56 & ojos traviesos de colegiala & $1-4 / / 1-4$ & \\
\hline \multirow[t]{2}{*}{57} & como los ojos de Louise Theo. & $1-4 / / 2-4$ & \\
\hline & Estrofa 11: & & \\
\hline 58 & Ágil, nerviosa, blanca, delgada, & $1-4 / / 1-4$ & \\
\hline 59 & media de seda bien restirada, & $1-4 / / 1-4$ & \\
\hline 60 & gola de encaje, corsé de crac, & $1-4 / / 2-4$ & \\
\hline 61 & nariz pequeña, garbosa, cuca, & $1-4 / / 2-4$ & \\
\hline 62 & y palpitantes sobre la nuca & $2-4 / / 1-4$ & \\
\hline \multirow[t]{2}{*}{63} & rizos tan rubios como el coñac. & $1-4 / / 1-4$ & \\
\hline & Estrofa 12: & & \\
\hline 64 & Sus ojos verdes bailan el tango; & $2-4 / / 1-4$ & \\
\hline 65 & nada hay más bello que el arremango & $1-4 / / 1-4$ & \\
\hline 66 & provocativo de su nariz. & $1-4 / / 1-4$ & \\
\hline 67 & Por ser tan joven y tan bonita & $2-4 / / 2-4$ & \\
\hline 68 & cual mi sedosa, blanca gatita, & $1-4 / / 1-4$ & \\
\hline \multirow[t]{2}{*}{69} & diera sus pajes la emperatriz. & $1-4 / / 1-4$ & \\
\hline & Estrofa 13: & & \\
\hline 70 & ¡Ah! Tú no has visto cuando se peina, & $2-4 / / 1-4$ & \\
\hline 71 & sobre sus hombros de rosa reina & $1-4 / / 2-4$ & \\
\hline 72 & caer los rizos en profusión. & $2-4 / / 1-4$ & \\
\hline 73 & Tú no has oído qué alegre canta, & $1-4 / / 1-4$ & \\
\hline 74 & mientras sus brazos y su garganta & $1-4 / / 1-4$ & \\
\hline 75 & de fresca espuma cubre el jabón. & $2-4 / / 1-4$ & \\
\hline
\end{tabular}




\begin{tabular}{|c|c|c|c|}
\hline No. & Verso & Acentos en sílabas: & Observaciones \\
\hline & Estrofa 14: & & \\
\hline 76 & Y los domingos, ¡con qué alegría!, & $1-4 / / 2-4$ & \\
\hline 77 & oye en su lecho bullir el día & $1-4 / / 2-4$ & \\
\hline 78 & ¡y hasta las nueve quieta se está! & $1-4 / / 1-4$ & \\
\hline 79 & ¡Cuál se acurruca la perezosa & $1-4 / / 1-4$ & \\
\hline 80 & bajo la colcha color de rosa, & $1-4 / / 2-4$ & \\
\hline \multirow[t]{2}{*}{81} & mientras a misa la criada va! & $1-4 / / 1-4$ & \\
\hline & Estrofa 15: & & \\
\hline 82 & La breve cofia de blanco encaje & $2-4 / / 2-4$ & \\
\hline 83 & cubre sus rizos, el limpio traje & $1-4 / / 2-4$ & \\
\hline 84 & aguarda encima del canapé. & $2-4 / / 1-4$ & \\
\hline 85 & Altas, lustrosas y pequeñitas, & $1-4 / / 1-4$ & \\
\hline 86 & sus puntas muestran las dos botitas, & $2-4 / / 2-4$ & \\
\hline \multirow[t]{2}{*}{87} & abandonadas del catre al pie. & $4 / / 2-4$ & $\begin{array}{l}\text { El primer hemistiquio es una sola } \\
\text { palabra }\end{array}$ \\
\hline & Estrofa 16: & & \\
\hline 88 & Después, ligera, del lecho brinca, & $2-4 / / 2-4$ & \\
\hline 89 & ¡oh quién la viera cuando se hinca & $2-4 / / 1-4$ & \\
\hline 90 & blanca y esbelta sobre el colchón! & $1-4 / / 1-4$ & \\
\hline 91 & ¿Qué valen junto de tanta gracia & $2-4 / / 2-4$ & \\
\hline 92 & las niñas ricas, la aristocracia, & $2-4 / / 1-4$ & \\
\hline \multirow[t]{2}{*}{93} & ni mis amigas del cotillón? & $2-4 / / 1-4$ & \\
\hline & Estrofa 17: & & \\
\hline 94 & Toco; se viste, me abre; almorzamos; & $1-4 / / 1-4$ & \\
\hline 95 & con apetito los dos tomamos & $1-4 / / 2-4$ & \\
\hline 96 & un par de huevos y un buen beefsteak, & $2-4 / / 2-4$ & \\
\hline 97 & media botella de rico vino, & $1-4 / / 2-4$ & \\
\hline 98 & y en coche, juntos, vamos camino & $2-4 / / 1-4$ & \\
\hline \multirow[t]{2}{*}{99} & del pintoresco Chapultepec. & $1-4 / / 4$ & El $2^{\circ}$ hemistiquio es una sola palabra \\
\hline & Estrofa 18: & & \\
\hline 100 & Desde las puertas de "La Sorpresa" & $1-4 / / 2-4$ & \\
\hline 101 & hasta la esquina del Jockey Club & $1-4 / / 2-4$ & \\
\hline 102 & no hay española, yanqui o francesa, & $1-4 / / 1-4$ & \\
\hline 103 & ni más bonita ni más traviesa & $2-4 / / 2-4$ & \\
\hline 104 & que la duquesa del duque Job. & $2-4 / / 2-4$ & \\
\hline
\end{tabular}


Como vemos, a lo largo de todo el poema, compuesto enteramente por versos decasílabos, predominan dos tipos de hemistiquios:

a). Con acentos en la primera sílaba y la cuarta: (ó-O-O)-(ó-o). Tomás Navarro Tomás designa a los versos en los que predominan este tipo de hemistiquios como "decasílabo dactílico compuesto". ${ }^{20} \mathrm{Y}$ está, en efecto, compuesto por un pie dactílico y uno trocaico.

b). Con acentos en la segunda y la cuarta: (o)-(ó-o)-(ó-o). Esto es: anacrusis monosílaba+trocaico+trocaico. A este tipo Navarro Tomás lo llama "decasílabo trocaico compuesto".

Podemos ver que en este poema Gutiérrez Nájera oscila entre ambos esquemas rítmicos, sin que predomine uno u otro. Hay muy pocos acentos antirrítmicos, y las licencias son, también, muy escasas: únicamente la diástole en el verso número 34 , donde el diptongo de la palabra "clientas" queda disuelto para que ajuste la medida:

Tabla 4

\begin{tabular}{|c|c|c|c|c|c|c|c|c|}
\hline $\mathrm{Ni}$ & las & di & en & $\operatorname{tas} / /$ & de He & Len & Ko & ssut \\
\hline 0 & ó & 0 & ó & o// & $\begin{array}{c}\circ \\
\text { sinalefa }\end{array}$ & ó & o & ó \\
\hline
\end{tabular}

En cuanto a la rima, que es consonante en la mayoría de casos, encontramos que, salvo las estrofas 1, 4, 7 y 18, que constan, cada una, de cinco versos, las demás estrofas son de seis versos decasílabos y, por lo general, riman: A-A-B-C-C-B. Son, por lo tanto, sex- tetos: estrofas de seis versos de arte mayor, y siguen la misma estructura de rimas que la de la célebre Sonatina, de Rubén Darío, con la salvedad de que este poema está constituido por versos alejandrinos, esto es, de catorce sílabas cada uno:

La princesa está triste..., ¿qué tendrá la princesa? 14A

Los suspiros se escapan de su boca de fresa, 14A

que ha perdido la risa, que ha perdido el color. 14B

La princesa está pálida en su silla de oro. 14C

Está mudo el teclado de su clave sonoro, 14C

y en un vaso, olvidada, se desmaya una flor. $14 \mathrm{~B}^{21}$

20 Navarro Tomás, Tomás (1974). 0. c. Pág. 9 y siguiente.

21 Fuente: https://www.retoricas.com/2015/04/ejemplos-de-sexteto.html\#: :targetText=El\%20Sexteto\%20es\%20una\%20Composici\%C3\%B 3n,isosil\%(3\%A1bicos)\%20y\%20de\%20rima\%20variable, consultado el 18 de noviembre de 2019. 
En cuanto a las estrofas de cinco versos, se trata de quintetos. En la estrofa 1 riman consonantemente los versos de acuerdo al esquema: A-A-B-A-B. en cambio, en la estrofa 4, riman A-B-A-A-B, igual que en la 7 y en la 18 , ya que se trata de estrofas exactamente iguales. En ambos casos se considera que la rima es consonante, siempre y cuando la pronunciación de la palabra "club" se asemeje a "clob".

Ejemplo de quinteto de arte mayor, concretamente en versos decasílabos, es el famoso poema del mexicano Ramón López Velarde titulado Suave Patria:

Suave Patria: te amo no cual mito, 11A sino por tu verdad de pan bendito, 11A como a niña que asoma por la reja $11 \mathrm{~B}$ con la blusa corrida hasta la oreja 11B y la falda bajada hasta el huesito. 11 $\mathrm{A}^{22}$

\subsection{Cómo lo dice. Segunda parte: Análisis retórico del poema}

En cuanto a las figuras retóricas, podemos decir que la estrofa número 1 está escrita en un estilo bastante directo. No encontramos en ese lugar ninguna imagen literaria. En cambio, en la estrofa número 2 tenemos una metáfora negativa continuada. El poeta nos va diciendo primero lo que el personaje central de la obra: la duquesa Job, no es: no es una falsa condesa, no es una muchacha pueblerina, u originaria de la ciudad de Puebla; no es una criadita, ni es una arribista.
En la estrofa número 3 continúa la metáfora negativa: no alardea de lo que no es (una gran señora). En cambio, es la griseta de Paul de Kock. No baila, no asiste a las carreras de caballos, ni toma el té a las cinco, todos placeres de la clase alta.

En la estrofa número 4 un símil le ayuda al autor a describir a su amada, a quien compara (plano evocado) con el sueño de un poeta y con los ángeles que subían y bajaban la escalera en la que el patriarca Jacob ascendió al cielo.

En la estrofa número 5, las alfombras que no pisa en su casa simbolizan la clase social a la que la protagonista, sin dudas, no pertenece. Tampoco se hace vestir por madame Marnat, sinécdoque esta que nos simboliza también la clase alta. Como corresponde a su extracción social, la duquesa Job va a "casa de otra modista", más acorde con su condición.

En la estrofa número 6 refuerza esta idea señalando que la duquesa Job "no tiene alhajas". Pero es tan hermosa que no le hacen falta, y afirma su buena figura y su elegancia.

En la estrofa número 7 aparece otra metáfora negativa: "no hay española, yanqui o francesa, ni más bonita ni más traviesa que la duquesa del duque Job”.

En la estrofa número 8 vemos una metáfora del tipo A de B: “talle de tentación”. En la estrofa siguiente advertimos un símil: "ella, ligera como una cebra".

22 Fuente: https://www.retoricas.com/2015/04/ejemplos-de-quinteto.html, consultado el 18 de noviembre de 2019. 
En la estrofa número 10 hay una metáfora continuada, en este caso del tipo A de B: "pie de andaluza, boa de guinda, sprint rociado de Veuve Clicquot, talle de avispa, cutis de ala, ojos traviesos de colegiala". Esta serie se cierra con otro símil: "como los ojos de Louise Theo".

En la estrofa número 11 asistimos a la aparición del epíteto mediante cuatro adjetivos en rápida sucesión: "ágil, nerviosa, blanca, delgada". Y luego sigue la metáfora continuada. El plano real es la joven Marie. Los planos evocados la describen a través de su atuendo. "media de seda bien restirada,/gola de encaje, corsé de crac". A continuación, sigue la descripción física de la muchacha: "nariz pequeña, garbosa, cuca,/ y palpitantes sobre la nuca/ rizos tan rubios como el coñac".

La estrofa número 12 se abre con una imagen poética de indiscutible novedad. "Sus ojos verdes bailan el tango". Luego sigue la descripción física, y al final, un símil: "Por ser tan joven y tan bonita/ cual mi sedosa, blanca gatita,/ diera sus pajes la emperatriz".

En la estrofa número 13 encontramos una metáfora del tipo A de B, cuando el poeta dice: "¡Ah! Tú no has visto cuando se peina,/ sobre sus hombros de rosa reina...".
En esta expresión: "hombros de rosa reina", reside la metáfora antes mencionada.

A continuación, en la estrofa número 14 hay otra imagen cuando el autor dice: "oye en su lecho bullir el día". En la estrofa siguiente hay una imagen de índole semejante, cuando señala: “...el limpio traje/aguarda encima del canapé...”.

Por el contrario, en las estrofas 16 y 17, aunque sugerente, el lenguaje es más bien directo. Tal vez únicamente cabe señalar la rápida sucesión de verbos, que también constituye una enumeración, al principio de la estrofa 17: "Toco; se viste, me abre; almorzamos...", serie que imprime un ritmo acelerado a esa parte del poema.

Para cerrar este artículo, tal vez convenga recordar, con Francisco Báez Rodríguez, que: "Gutiérrez Nájera... está eternizado en el mural Sueño de una tarde dominical en la Alameda, de Diego Rivera. ${ }^{23}$ Es el señor elegante, debajo de los globos, que se quita el sombrero ante dos damas que pasean por el parque: mujeres que — como Marie, su duquesita- empezaban a adueñarse de la calle y de la ciudad". Y se adueñaron para quedarse en la realidad y en el sueño. ¿Qué duda cabe?

23 Sueño de una tarde dominical en la Alameda Central es un mural que fue pintado por Diego Rivera (1887-1957) en 1947. La obra se creó a iniciativa del arquitecto Carlos Obregón Santacilia y se encontraba originalmente en el restaurante Versailles del Hotel del Prado, hasta que este edificio fue dañado por el terremoto del 10 de octubre de 1985. Tras su restauración, la obra fue trasladada a su ubicación actual en el Museo Mural "Diego Rivera", de la ciudad de México. Tiene unas dimensiones de $15.6 \mathrm{~m} \times 4.7 \mathrm{~m}$. En el cuadro desfilan treinta personajes de la historia del país azteca, como Hernán Cortés, Sor Juana Inés de la Cruz, el primer obispo de México: fray Juan de Zumárraga, Benito Juárez, Porfirio Díaz, el emperador Maximiliano y su esposa Carlota, el poeta cubano José Martí, el grabador José Guadalupe Posada, originario de Aguascalientes, y su inmortal creación: La Catrina, alegoría popular de la Muerte, y el héroe revolucionario Emiliano Zapata, entre otros. 


\section{Referencias}

Baehr, Rudolf (1973). Manual de versificación española. Madrid, Gredos, ISBN 84-249-1176-8.

Báez Rodríguez, Francisco (2012), Hermenéutica de La Duquesa Job, publicado el 2 de abril de 2012, y consultado el 13 de septiembre de 2019, en: http://donsusanito.blogspot.com/2012/04/hermeneutica-de-laduquesa-job.html. Don Susanito es el pseudónimo del bloguero Francisco Báez Rodríguez, periodista mexicano y columnista del periódico La Crónica de Hoy.

Henríquez Ureña, Max (1962). Breve historia del modernismo. Ciudad de México, Fondo de Cultura Económica. Sin ISBN.

Figueroa Obregón, Rodrigo (2019). Espacio político en “La duquesa Job" de Manuel Gutiérrez Nájera. En Decimonónica. Journal of Nineteenth Century Hispanic Cultural Production. Revista de Producción Cultural Hispánica Decimonónica. Vol. 16, No. 1.

Jiménez Cervantes-Arnao, María del Mar (2008). Un aná- lisis de la traducción de "Stella" de Víctor Hugo, por Francisco Gavidia. Artículo publicado en Cartaphilus. Revista de investigación y crítica estética. Hay versión digital en: https://revistas.um.es/ cartaphilus/article/view/23561, consultado el 28 de octubre de 2019.

Navarro Tomás, Tomás (1974). Métrica española. Madrid, Ediciones Guadarrama. ISBN 84-250-5603-9.

Pacheco, José Emilio (2000). Manuel Gutiérrez Nájera: el sueño de una noche porfiriana. En Letras Libres. Ciudad de México. Versión digital: https://www.letraslibres.com/mexico/manuel-gutierrez-najera-elsueno-una-noche-porfiriana

Quilis, Antonio (1997). Métrica española. Barcelona, Ariel. ISBN 8434483084.

Vela, Arqueles (2005). El modernismo: su filosofía, su estética, su técnica. Ciudad de México, Ed. Porrúa. ISBN 970-07-5740-4 
